\title{
Neodymium improves the activity of ascorbate-glutathione cycle and chloroplast function of wheat seedlings under chromium stress
}

\author{
N.H. LU*,, L.M. WU*, R. YANG*, H. LI**, and C.J. SHAN*,+ \\ Henan Institute of Science and Technology, 453003 Xinxiang, China* \\ School of Life Sciences, Henan University, 475004 Kaifeng, China**
}

\begin{abstract}
We investigated the roles of neodymium trichloride $\left(\mathrm{NdCl}_{3}\right)$ in regulating ascorbate-glutathione (AsA-GSH) cycle and chloroplast function of chromium (Cr)-stressed wheat seedlings. The findings showed that $\mathrm{Cr}$ stress markedly increased malondialdehyde (MDA) content, electrolytic leakage (EL), nonphotochemical quenching, and the activities of enzymes in AsA-GSH cycle, compared with control. However, Cr stress markedly reduced the ratios of reduced ascorbate to dehydroascorbate and reduced glutathione to oxidized glutathione, net photosynthetic rate, the contents of chlorophylls and carotenoids, maximum photochemical efficiency of PSII, photochemical quenching, and quantum efficiency of PSII photochemistry, as well as plant height, root length, and plant biomass. $\mathrm{NdCl}_{3}$ plus $\mathrm{Cr}$ stress markedly reduced MDA content and EL and improved other indicators, compared with $\mathrm{Cr}$ stress alone. Meanwhile, $\mathrm{NdCl}_{3}$ alone also markedly improved above indicators except MDA and EL, compared with control. Current results implied that $\mathrm{NdCl}_{3}$ improved AsA-GSH cycle and chloroplast function of wheat seedlings under $\mathrm{Cr}$ stress.
\end{abstract}

Additional key words: chromium tolerance; Halliwell-Asada pathway; photosynthesis; Triticum aestivum L.

\section{Introduction}

Chromium (Cr) stress has significant inhibitory effects on plant growth and development (Qing et al. 2015). Cr stress usually leads to the excessive production of reactive oxygen species (ROS), which further causes oxidative stress to plants (Karuppanapandian et al. 2006). In fact, plants have a complicated antioxidant protection system to fight against oxidative stress. In plants, the ascorbateglutathione (AsA-GSH) cycle is a very vital part of the antioxidant protection system (Ahmad et al. 2018). AsAGSH cycle is composed of four enzymes, such as ascorbate peroxidase (APX), monodehydroascorbate reductase (MDHAR), dehydroascorbate reductase (DHAR), and glutathione reductase (GR). Through the catalytic action of above four enzymes, hydrogen peroxide is scavenged and two important antioxidants, AsA and GSH, are regenerated. Thus, AsA-GSH cycle has a vital role in cleaning up $\mathrm{H}_{2} \mathrm{O}_{2}$ and maintaining the redox equilibrium of plant cells.

Rare earth elements (REEs) have obvious positive effects on plant growth, plant production, and fruit quality (Ouyang et al. 2003, Shan et al. 2017, 2018). Lanthanum (La) and cerium (Ce) are two important REEs. In plants, an increasing number of studies was focused on the roles of $\mathrm{La}$ and $\mathrm{Ce}$ in alleviating the oxidative stress induced by heavy metal stress (Wang et al. 2013, Dai et al. 2017). Neodymium (Nd) is also an important member of REEs. However, there is still no report about the roles of $\mathrm{Nd}$ in regulating the antioxidative responses of plants to $\mathrm{Cr}$ stress. Therefore, it is meaningful to clarify whether and how $\mathrm{Nd}$ affects the antioxidant capacity of $\mathrm{Cr}$-stressed plants through AsA-GSH cycle.

Chloroplast function has a close relationship with plant growth. The results of Xue et al. (2018) showed that Cr stress decreased the photosynthetic activity of chloroplasts. However, there is also still no report about the effects of Nd on the photosynthetic activity of chloroplasts, especially under $\mathrm{Cr}$ stress. Thus, it is also meaningful to clarify whether and how $\mathrm{Nd}$ affects the photosynthetic activity of chloroplasts under $\mathrm{Cr}$ stress.

In current study, we investigated the effects of neodymium trichloride $\left(\mathrm{NdCl}_{3}\right)$ on the activities of enzymes in AsA-GSH cycle, the ratios of reduced ascorbate to dehydroascorbate (AsA/DHA) and reduced glutathione to oxidizided glutathione (GSH/GSSG), malondialdehyde (MDA) content and electrolytic leakage (EL), net photosynthetic rate $\left(P_{\mathrm{N}}\right)$, chlorophyll fluorescence parameters, the contents of chlorophylls (Chl) and carotenoids (Car),

\footnotetext{
Received 24 November 2019, accepted 16 March 2020.

+Corresponding author; e-mail: luninghai2019@aliyun.com, shanchangjuan1978@163.com

Abbreviations: APX - ascorbate peroxidase; AsA - reduced ascorbate; AsA/DHA - the ratio of reduced ascorbate to dehydroascorbate; AsA-GSH - ascorbate-glutathione; Car - carotenoids; DHAR - dehydroascorbate reductase; EL - electrolyte leakage; $\mathrm{F}_{\mathrm{v}} / \mathrm{F}_{\mathrm{m}}-$ maximum photochemical efficiency of PSII; GR - glutathione reductase; GSH - reduced glutathione; GSH/GSSG - the ratio of reduced glutathione to oxidized glutathione; MDA - malondialdehyde; MDHAR - monodehydroascorbate reductase; $P_{\mathrm{N}}-$ net photosynthetic rate; $\mathrm{q}_{\mathrm{N}}$ - nonphotochemical quenching; $\mathrm{q}_{\mathrm{P}}$ - photochemical quenching; $\Phi_{\mathrm{PSII}}-$ effective quantum yield of PSII.

Acknowledgements: The present study was supported by National Key Research Project (2017YFD0201704), Province Science and Technology Research Project (172102110023), and Henan Provincial Key Scientific Research Project (17A210004).
} 
as well as plant height and biomass of Cr-stressed wheat seedlings. The aim of this study was to elucidate the effects of $\mathrm{NdCl}_{3}$ on AsA-GSH cycle and chloroplast function of Cr-stressed wheat seedlings, which will provide new information for its application in enhancing $\mathrm{Cr}$ tolerance of wheat crops.

\section{Materials and methods}

Plant material and treatments: The seeds of wheat (Triticum aestivum L.) cultivar Bainong 207 were germinated and cultured in the manual climatic box ( $G X M-$ 358, Beijing Century Sunshine Technology Development Co., Ltd., China). The temperature of day/night periods, photoperiod, and photosynthetic active radiation were set as $25 / 15^{\circ} \mathrm{C}, 12 \mathrm{~h}$, and $500 \mu \mathrm{mol}$ (photon) $\mathrm{m}^{-2} \mathrm{~s}^{-1}$, respectively. After the second leaves were fully expanded, the roots of plants were placed in half-strength Hoagland's solution, which was replaced every second day. After the third leaves were fully expanded, plants with similar growth status were chosen for our study.

The suitable treatment concentration of $\mathrm{CrCl}_{3}$ was selected from 20, 40, 80, and $120 \mathrm{mg}\left(\mathrm{CrCl}_{3}\right) \mathrm{L}^{-1}$. After $48 \mathrm{~h}$ of treatment, we observed obvious wilting phenomenon for plants treated by $120 \mathrm{mg}\left(\mathrm{CrCl}_{3}\right) \mathrm{L}^{-1}$, while no obvious wilting phenomenon was observed for plants treated by 20 and $40 \mathrm{mg}\left(\mathrm{CrCl}_{3}\right) \mathrm{L}^{-1}$. However, there was only slight wilting phenomenon for plants treated by $80 \mathrm{mg}\left(\mathrm{CrCl}_{3}\right) \mathrm{L}^{-1}$. Thus, $80 \mathrm{mg}\left(\mathrm{CrCl}_{3}\right) \mathrm{L}^{-1}$ was selected as the suitable concentration for $\mathrm{Cr}$ treatment in this study. To investigate the effect of $\mathrm{Cr}$ stress, the roots of wheat seedlings were treated by $80 \mathrm{mg}\left(\mathrm{CrCl}_{3}\right) \mathrm{L}^{-1}$ for $48 \mathrm{~h}$. Then we investigated the effects of different concentrations of $\mathrm{NdCl}_{3}$ on MDA content and plant biomass, and selected $30 \mu \mathrm{M} \mathrm{NdCl}{ }_{3}$ as the suitable concentration for the current study. Then, the roots of plants were firstly placed in $30 \mu \mathrm{M} \mathrm{NdCl}_{3}$ for $12 \mathrm{~h}$ and then treated by Cr stress or Hoagland's solution for $48 \mathrm{~h}$. Control plants were only treated by $30 \mu \mathrm{M}$ $\mathrm{NdCl}_{3}$ or Hoagland's solution. All solutions were prepared by dissolving corresponding chemicals in Hoagland's solution. After $48 \mathrm{~h}$ of treatment, top fully expanded leaves of wheat seedlings under different treatments were sampled and stored in liquid nitrogen and then used for measurements.

Assays of antioxidant enzymes: The extraction and activity of APX (EC 1.11.1.11) was done according to Han et al. (2015) and Nakano and Asada (1981). The extraction and activities of GR (EC 1.6.4.2) and DHAR (EC 1.8.5.1) were done according to Singh et al. (2018) and Dalton et al. (1986), respectively. The extraction and activity of MDHAR (EC 1.6.5.4) was done according to Li et al. (2015). One unit of APX activity was defined as the amount of APX catalyzing the oxidation of $1 \mu \mathrm{mol}$ AsA per min. One unit of GR activity was defined as the reduction of $1 \mu$ mol NADPH per min. One unit of MDHAR activity was defined as the amount of enzyme that oxidizes $1 \mu \mathrm{mol}$ NADH per min. One unit of DHAR activity was defined as the amount of enzyme that produces $1 \mu \mathrm{mol}$ AsA per min. The specific activities of these enzymes were expressed as units $\mathrm{mg}^{-1}$ (protein). Protein concentration was analysed according to Bradford (1976). TU-1810 UV-Vis spectrophotometer (Beijing Purkinje General Instrument Co., Ltd., China) was used for activity measurements.

Analysis of AsA/DHA and GSH/GSSG: AsA and DHA were analysed according to Hodges et al. (1996) and Zhao et al. (2018). The ratio of AsA/DHA was expressed by the ratio of AsA content to DHA content. GSSG and GSH were analysed according to Li et al. (2018). The ratio of GSH/GSSG was expressed by the ratio of GSH content to GSSG content.

Analysis of MDA content and EL: The content of MDA was analysed according to Heath and Packer (1968) and Wang et al. (2018). TU-1810 UV-vis spectrophotometer (Beijing Purkinje General Instrument Co., Ltd., China) was used for MDA measurement. EL was analysed according to Anjum et al. (2015) and Yu et al. (2018). DDSJ-308 conductivity meter (Shanghai Leici Instrument Co., Ltd., China) was used for EL measurement.

$\boldsymbol{P}_{\mathrm{N}}$ and chlorophyll (Chl) fluorescence parameters: After $48 \mathrm{~h}$ of treatment, $P_{\mathrm{N}}$ was determined by photosynthesis system (Licor-6400, USA) from 10:00 to 12:00 h. The top expanded leaves of different treatments were first equilibrated at a photosynthetic photon flux density of 700 $\mu \mathrm{mol} \mathrm{m} \mathrm{m}^{-2} \mathrm{~s}^{-1}, 26^{\circ} \mathrm{C}$, an ambient $\mathrm{CO}_{2}$ concentration of 300 $\mu \mathrm{mol} \mathrm{mol}{ }^{-1}$, and a vapour pressure difference between leaf and air of $1.0-1.2 \mathrm{kPa}$. After equilibration, steady-state gas-exchange values were recorded. Chl fluorescence parameters, such as maximum photochemical efficiency of PSII $\left(\mathrm{F}_{\mathrm{v}} / \mathrm{F}_{\mathrm{m}}\right)$, photochemical quenching $\left(\mathrm{q}_{\mathrm{P}}\right)$, nonphotochemical quenching $\left(\mathrm{q}_{\mathrm{N}}\right)$, and quantum efficiency of PSII photochemistry $\left(\Phi_{\mathrm{PSII}}\right)$ were determined by a Yaxin-1161G fluorometer (Yaxin, China) from 10:00 to 12:00 h. Measurements were performed in a closed chamber under controlled growth conditions. Minimum fluorescence $\left(\mathrm{F}_{0}\right)$ was measured under a weak modulating radiation $[0.5$ $\mu \mathrm{mol}$ (photon) $\mathrm{m}^{-2} \mathrm{~s}^{-1}$, and maximum fluorescence $\left(\mathrm{F}_{\mathrm{m}}\right)$ was inducedbyasaturatingpulseofradiation $[2,400 \mu \mathrm{mol}($ photon) $\left.\mathrm{m}^{-2} \mathrm{~s}^{-1}\right]$.

Assays of Chl and Car: Top fully expanded leaves were used to determine the contents of Chl and Car according to Lichtenthaler and Wellburn (1983) and Song et al. (2016). TU-1810 UV-Vis spectrophotometer (Beijing Purkinje General Instrument Co., Ltd., China) was used for the assays of $\mathrm{Chl}$ and Car.

Plant height, root length, and plant biomass: After $7 \mathrm{~d}$ of treatment, the ruler was used to measure root length and plant height. Fresh masses of plants under different treatments were recorded and dried in the oven for $96 \mathrm{~h}$ at $80^{\circ} \mathrm{C}$. Then dry masses were recorded.

Measurement of Nd and Cr: After $7 \mathrm{~d}$ of treatment, each dry sample of roots and leaves was ground and mixed thoroughly. Fine powder $(0.5 \mathrm{~g})$ of each dry sample was digested in a mixture of $7 \mathrm{ml}$ of $\mathrm{HNO}_{3}+1 \mathrm{ml}$ of $\mathrm{HClO}_{4}$ 
at $170^{\circ} \mathrm{C}$ according to Dai et al. (2017). Then the contents of $\mathrm{Nd}$ and $\mathrm{Cr}$ in extracts were measured by flame atomic absorbance spectrometry (Hitachi 180-80, Kyoto, Japan).

Table 1. Effects of different concentrations of $\mathrm{NdCl}_{3}$ on malondialdehyde (MDA) content and plant biomass of wheat under $\mathrm{Cr}$ stress. The plants were treated as below. Control - half-strength Hoagland's solution; $\mathrm{Cr}-80 \mathrm{mg} \mathrm{L}{ }^{-1} \mathrm{CrCl}_{3} ; 10 \mu \mathrm{M} \mathrm{Nd}+\mathrm{Cr}-$ $10 \mu \mathrm{M} \mathrm{NdCl}_{3}+80 \mathrm{mg} \mathrm{L}^{-1} \mathrm{CrCl}_{3} ; 30 \mu \mathrm{M} \mathrm{Nd}+\mathrm{Cr}-30 \mu \mathrm{M}$ $\mathrm{NdCl}_{3}+80 \mathrm{mg} \mathrm{L}^{-1} \mathrm{CrCl}_{3} ; 50 \mu \mathrm{M} \mathrm{Nd}+\mathrm{Cr}-50 \mu \mathrm{M} \mathrm{NdCl}_{3}+$ $80 \mathrm{mg} \mathrm{L}^{-1} \mathrm{CrCl}_{3} ; 100 \mu \mathrm{M} \mathrm{Nd}+\mathrm{Cr}-100 \mu \mathrm{M} \mathrm{NdCl}_{3}+80 \mathrm{mg} \mathrm{L}^{-1}$ $\mathrm{CrCl}_{3}$. The plants were firstly treated by $\mathrm{NdCl}_{3}$ for $12 \mathrm{~h}$, and then treated by $\mathrm{Cr}$ stress or half-strength Hoagland's solution. After $48 \mathrm{~h}$ of treatment, MDA content was determined. After $7 \mathrm{~d}$ of treatment, plant biomass was determined. Values are means \pm $\mathrm{SD}, n=6$. Different lowercase letters mean statistical difference at $5 \%$ level of significance.

\begin{tabular}{lcc}
\hline Treatment & $\begin{array}{l}\text { MDA } \\
{\left[\mathrm{nmol} \mathrm{g}^{-1}(\mathrm{FM})\right]}\end{array}$ & $\begin{array}{l}\text { Plant biomass } \\
{\left[\mathrm{mg}(\mathrm{FM}) \text { plant }^{-1}\right]}\end{array}$ \\
\hline Control & $5.00 \pm 0.43^{\mathrm{e}}$ & $108.00 \pm 11.30^{\mathrm{a}}$ \\
$\mathrm{Cr}$ & $13.90 \pm 1.27^{\mathrm{b}}$ & $80.30 \pm 9.24^{\mathrm{c}}$ \\
$10 \mu \mathrm{M} \mathrm{Nd}+\mathrm{Cr}$ & $12.00 \pm 1.11^{\mathrm{c}}$ & $85.60 \pm 7.48^{\mathrm{bc}}$ \\
$30 \mu \mathrm{M} \mathrm{Nd}+\mathrm{Cr}$ & $9.70 \pm 0.89^{\mathrm{d}}$ & $95.90 \pm 9.15^{\mathrm{b}}$ \\
$50 \mu \mathrm{M} \mathrm{Nd}+\mathrm{Cr}$ & $12.50 \pm 1.15^{\mathrm{c}}$ & $83.40 \pm 7.99^{\mathrm{bc}}$ \\
$100 \mu \mathrm{M} \mathrm{Nd}+\mathrm{Cr}$ & $15.90 \pm 1.81^{\mathrm{a}}$ & $71.00 \pm 8.34^{\mathrm{d}}$ \\
\hline
\end{tabular}

Statistical analysis: The data in tables and figures were the mean of six replications. Means were compared by one-way analysis of variance (ANOVA) and Duncan's multiple range test at 5\% level of significance. SPSS 19.0 was used for statistical analysis.

\section{Results}

MDA content and plant biomass: To select the suitable concentration of $\mathrm{NdCl}_{3}$, we investigated the effects of different $\mathrm{NdCl}_{3}$ concentrations $(10,30,50$, and $100 \mu \mathrm{M}$ $\mathrm{NdCl}_{3}$ ) on MDA content in leaves and plant biomass of Cr-stressed wheat seedlings. Among different concentrations, $30 \mu \mathrm{M} \mathrm{NdCl}_{3}$ markedly decreased MDA content in leaves and increased plant biomass of Cr-stressed wheat seedlings (Table 1). Based on above findings, we selected $30 \mu \mathrm{M} \mathrm{NdCl}_{3}$ as the suitable concentration for this study.

Activities of enzymes in AsA-GSH cycle: Compared with control, $\mathrm{Cr}$ stress markedly improved the activities of enzymes in AsA-GSH cycle, including APX, GR, DHAR, and MDHAR (Fig. 1). Application of $\mathrm{NdCl}_{3}$ plus $\mathrm{Cr}$ stress markedly enhanced the activities of above four enzymes, compared to $\mathrm{Cr}$ stress alone. Application of $\mathrm{NdCl}_{3}$ plus $\mathrm{Cr}$ stress improved the activities of APX, GR, DHAR, and MDHAR by $34.2,34.0,50.8$, and $35.6 \%$, respectively. At the same time, $\mathrm{NdCl}_{3}$ alone also markedly enhanced the activities of above four enzymes, compared

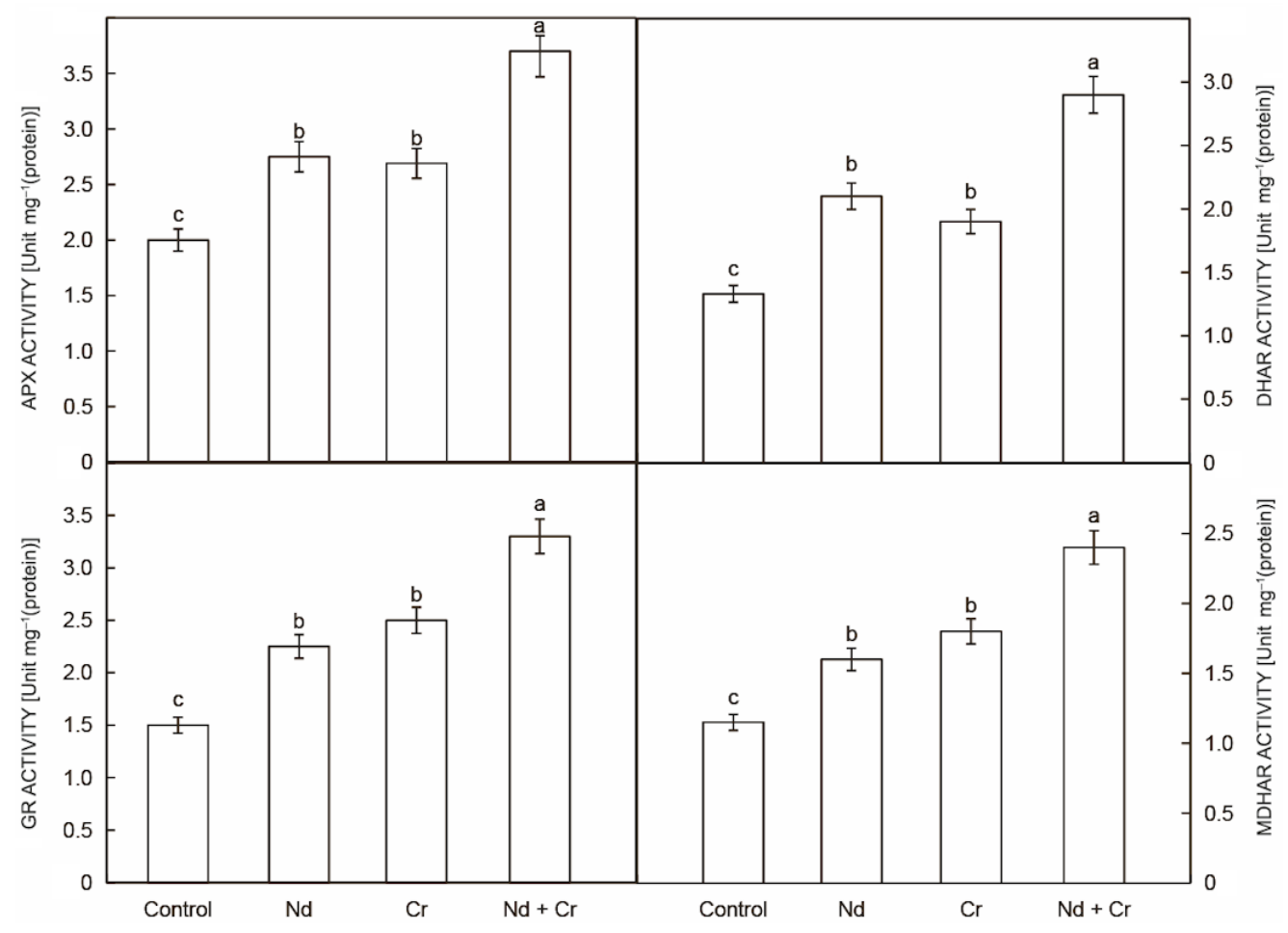

Fig. 1. Effects of Nd on the activities of ascorbate peroxidase (APX), glutathione reductase (GR), dehydroascorbate reductase (DHAR), and monodehydroascorbate reductase (MDHAR) of wheat under Cr stress. The plants were treated as below. Control - half-strength Hoagland's solution; $\mathrm{Nd}-30 \mu \mathrm{M} \mathrm{NdCl}_{3} ; \mathrm{Cr}-80 \mathrm{mg} \mathrm{L}^{-1} \mathrm{CrCl}_{3} ; \mathrm{Nd}+\mathrm{Cr}-30 \mu \mathrm{M} \mathrm{NdCl}_{3}+80 \mathrm{mg} \mathrm{L} \mathrm{CrCl}_{3}$. The plants were firstly treated by $\mathrm{NdCl}_{3}$ for $12 \mathrm{~h}$, and then treated by Cr stress for $48 \mathrm{~h}$. Values are means $\pm \mathrm{SD}, n=6$. Different lowercase letters mean statistical difference at $5 \%$ level of significance. 


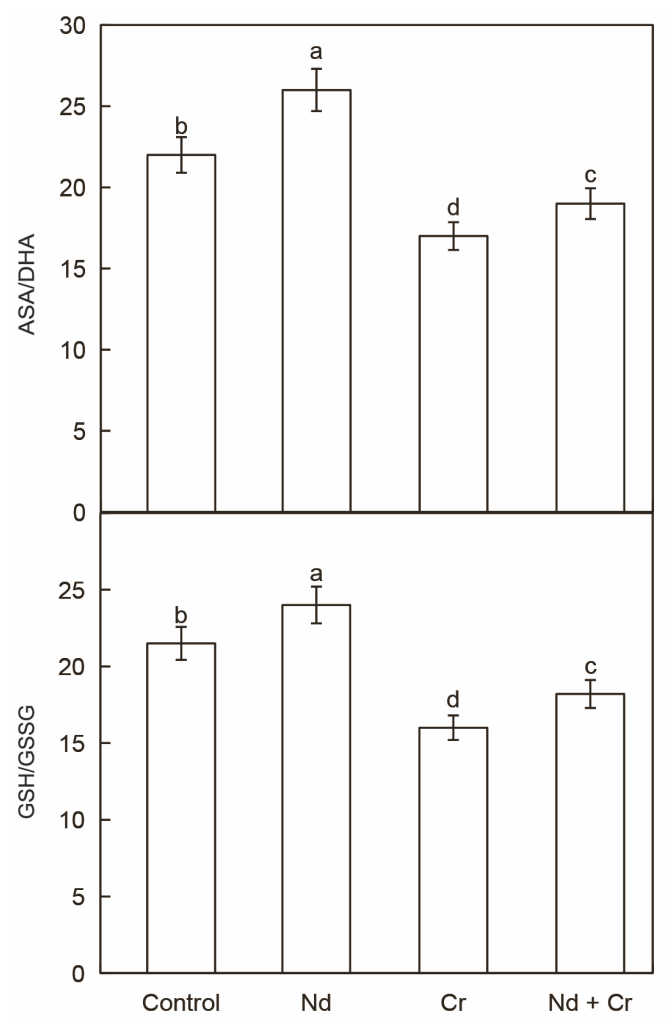

Fig. 2. Effects of $\mathrm{Nd}$ on the ratio of reduced ascorbate to dehydroascorbate (AsA/DHA) and the ratio of reduced glutathione to oxidized glutathione (GSH/GSSG) of wheat under $\mathrm{Cr}$ stress. The plants were treated as below. Control - half-strength Hoagland's solution; $\mathrm{Nd}-30 \mu \mathrm{M} \mathrm{NdCl}_{3} ; \mathrm{Cr}-80 \mathrm{mg} \mathrm{L}^{-1} \mathrm{CrCl}_{3}$; $\mathrm{Nd}+\mathrm{Cr}-30 \mu \mathrm{M} \mathrm{NdCl}{ }_{3}+80 \mathrm{mg} \mathrm{L}^{-1} \mathrm{CrCl}_{3}$. The plants were firstly treated by $\mathrm{NdCl}_{3}$ for $12 \mathrm{~h}$, and then treated by $\mathrm{Cr}$ stress for $48 \mathrm{~h}$. Values are means $\pm \mathrm{SD}, n=6$. Different lowercase letters mean statistical difference at $5 \%$ level of significance.

with control. Current results implied that $\mathrm{NdCl}_{3}$ enhanced the antioxidant capacity of Cr-stressed wheat seedlings through AsA-GSH cycle.

Redox states of AsA and GSH: Cr stress markedly reduced AsA/DHA and GSH/GSSG in the leaves of wheat seedlings, compared with control (Fig. 2). Application of $\mathrm{NdCl}_{3}$ plus $\mathrm{Cr}$ stress markedly increased above two ratios, compared to $\mathrm{Cr}$ stress alone. Application of $\mathrm{NdCl}_{3}$ plus $\mathrm{Cr}$ stress increased AsA/DHA and GSH/GSSG by 13.5 and $13.9 \%$, respectively. At the same time, $\mathrm{NdCl}_{3}$ alone also markedly improved above two ratios, compared with control. Combined with the effects of $\mathrm{NdCl}_{3}$ on AsA-GSH cycle, our present results suggested that $\mathrm{NdCl}_{3}$ could modulate the redox states of AsA and GSH via AsA-GSH cycle under Cr stress.

$\boldsymbol{P}_{\mathrm{N}}, \mathrm{Chl}$ fluorescence parameters, and the contents of Chl and Car: Compared with control, Cr stress markedly decreased $P_{\mathrm{N}}, \mathrm{F}_{\mathrm{v}} / \mathrm{F}_{\mathrm{m}}, \mathrm{q}_{\mathrm{P}}, \Phi_{\mathrm{PSII}}$, and the contents of $\mathrm{Chl}$ and Car, but markedly increased $\mathrm{q}_{\mathrm{N}}$ in leaves (Table 2). Application of $\mathrm{NdCl}_{3}$ plus $\mathrm{Cr}$ stress markedly improved above indicators, compared with $\mathrm{Cr}$ stress alone. Applica- tion of $\mathrm{NdCl}_{3}$ plus $\mathrm{Cr}$ stress improved $\mathrm{F}_{\mathrm{v}} / \mathrm{F}_{\mathrm{m}}, \mathrm{q}_{\mathrm{P}}, \mathrm{q}_{\mathrm{N}}, \Phi_{\mathrm{PSII}}$, $P_{\mathrm{N}}$, and the contents of $\mathrm{Chl}$ and Car by $22.8,23.5,18.2$, $20.0,23.4,14.8$, and $26.3 \%$, respectively. At the same time, $\mathrm{NdCl}_{3}$ alone also markedly improved above indicators, compared with control. Combined with the effects of $\mathrm{NdCl}_{3}$ on AsA-GSH cycle, the present findings suggested that $\mathrm{NdCl}_{3}$ improved the function of PSII by enhancing AsA-GSH cycle under Cr stress.

Nd and $\mathrm{Cr}$ content: $\mathrm{Cr}$ stress markedly enhanced the contents of $\mathrm{Cr}$ in roots and leaves, in comparison with control (Table 3). Application of $\mathrm{NdCl}_{3}$ plus $\mathrm{Cr}$ stress markedly reduced the contents of $\mathrm{Cr}$ in roots and leaves, in comparison with $\mathrm{Cr}$ stress alone. Application of $\mathrm{NdCl}_{3}$ plus $\mathrm{Cr}$ stress reduced the contents of $\mathrm{Cr}$ in roots and leaves by 32.2 and $33.7 \%$, respectively. Meanwhile, $\mathrm{NdCl}_{3}$ alone markedly increased the contents of $\mathrm{Nd}$ in roots and leaves, in comparison with control. Application of $\mathrm{NdCl}_{3}$ plus $\mathrm{Cr}$ stress also markedly improved the contents of $\mathrm{Nd}$ in roots and leaves, compared with $\mathrm{Cr}$ stress alone. These findings demonstrated that $\mathrm{NdCl}_{3}$ had an alleviating effect on $\mathrm{Cr}$ toxicity by reducing the absorption of $\mathrm{Cr}$ by the roots and leaves of wheat crops.

MDA content, root length, plant height, and biomass: In comparison with control, Cr stress markedly increased EL and MDA content, and decreased root length, plant height, and biomass (Table 4). In comparison with Cr stress alone, application of $\mathrm{NdCl}_{3}$ plus Cr stress markedly reduced EL and MDA content, and improved root length, plant height, and biomass. Application of $\mathrm{NdCl}_{3}$ plus $\mathrm{Cr}$ stress reduced EL and MDA content by 31.5 and $32.3 \%$, respectively. After $7 \mathrm{~d}$ of treatment, application of $\mathrm{NdCl}_{3}$ plus $\mathrm{Cr}$ stress enhanced root length, plant height, and biomass by 23.2 , 18.3 , and $17.6 \%$, respectively. At the same time, $\mathrm{NdCl}_{3}$ alone also markedly decreased EL and MDA content, and improved root length, plant height, and biomass, in comparison with control. These findings demonstrated that $\mathrm{NdCl}_{3}$ had an alleviating effect on $\mathrm{Cr}$ toxicity.

\section{Discussion}

Many studies showed that heavy metal stress caused oxidative stress to plants, including Cr stress (Tan et al. 2014, Zhang et al. 2014, Mahmud et al. 2017). Our present study also showed that $\mathrm{Cr}$ stress markedly increased EL and MDA content in leaves. Thus, our findings indicated that Cr stress could also cause oxidative stress to wheat plants.

Karuppanapandian et al. (2006) reported that $\mathrm{Cr}$ stress had obvious effects on AsA-GSH cycle in green gram. Farid et al. (2018) showed that Cr stress upregulated APX activity in sunflower. Kabir (2016) reported that Cr stress markedly improved GR activity in rice seedlings. Above previous studies were focused on cereal crops, rice, and horticultural crops (Ma et al. 2016, Mahmud et al. 2017). However, there is still few reports about the effects of $\mathrm{Cr}$ stress on wheat crops. In our present study, the activity of AsA-GSH cycle in wheat seedlings leaves was enhanced to cope with the oxidative stress induced by $\mathrm{Cr}$ stress, which agreed with the results of Karuppanapandian et al. 
Table 2. Effects of $\mathrm{NdCl}_{3}$ on chlorophyll fluorescence parameters, net photosynthetic rate, and chlorophylls and carotenoids contents of wheat under $\mathrm{Cr}$ stress. The plants were treated as below. Control - half-strength Hoagland's solution; $\mathrm{Nd}-30 \mu \mathrm{M} \mathrm{NdCl}_{3} ; \mathrm{Cr}_{-}-80 \mathrm{mg} \mathrm{L}{ }^{-1}$ $\mathrm{CrCl}_{3} ; \mathrm{Nd}+\mathrm{Cr}-30 \mu \mathrm{M} \mathrm{NdCl}_{3}+80 \mathrm{mg} \mathrm{L}^{-1} \mathrm{CrCl}_{3}$. The plants were firstly treated by $\mathrm{NdCl}_{3}$ for $12 \mathrm{~h}$, and then treated by $\mathrm{Cr}$ stress for $48 \mathrm{~h}$. Car - carotenoids; $\mathrm{F}_{\mathrm{v}} / \mathrm{F}_{\mathrm{m}}$ - maximum photochemical efficiency of PSII; $P_{\mathrm{N}}-$ net photosynthetic rate; $\mathrm{q}_{\mathrm{N}}$ - nonphotochemical quenching; $\mathrm{q}_{\mathrm{P}}$ - photochemical quenching; $\Phi_{\mathrm{PSII}}-$ effective quantum yield of PSII. Values are means $\pm \mathrm{SD}, n=6$. Different lowercase letters mean statistical difference at $5 \%$ level of significance.

\begin{tabular}{llllllll}
\hline Treatment & $\mathrm{F}_{\mathrm{v}} / \mathrm{F}_{\mathrm{m}}$ & $\mathrm{q}_{\mathrm{P}}$ & $\mathrm{q}_{\mathrm{N}}$ & $\Phi_{\text {PSII }}$ & $\begin{array}{l}P_{\mathrm{N}} \\
{\left[\mu \mathrm{mol} \mathrm{m}^{-2} \mathrm{~s}^{-1}\right]}\end{array}$ & $\begin{array}{l}\text { Chl } \\
{\left[\mathrm{mg} \mathrm{g}^{-1}(\mathrm{FM})\right]}\end{array}$ & $\begin{array}{l}\text { Car } \\
{\left[\mathrm{mg} \mathrm{g}^{-1}(\mathrm{FM})\right]}\end{array}$ \\
\hline Control & $0.80 \pm 0.08^{\mathrm{b}}$ & $0.51 \pm 0.07^{\mathrm{b}}$ & $0.21 \pm 0.02^{\mathrm{d}}$ & $0.43 \pm 0.06^{\mathrm{b}}$ & $7.00 \pm 0.63^{\mathrm{b}}$ & $2.17 \pm 0.27^{\mathrm{b}}$ & $0.63 \pm 0.06^{\mathrm{b}}$ \\
$\mathrm{Nd}$ & $0.88 \pm 0.10^{\mathrm{a}}$ & $0.58 \pm 0.06^{\mathrm{a}}$ & $0.26 \pm 0.03^{\mathrm{c}}$ & $0.50 \pm 0.08^{\mathrm{a}}$ & $8.10 \pm 0.90^{\mathrm{a}}$ & $2.43 \pm 0.23^{\mathrm{a}}$ & $0.75 \pm 0.09^{\mathrm{a}}$ \\
$\mathrm{Cr}$ & $0.57 \pm 0.07^{\mathrm{d}}$ & $0.34 \pm 0.04^{\mathrm{d}}$ & $0.33 \pm 0.05^{\mathrm{b}}$ & $0.30 \pm 0.04^{\mathrm{d}}$ & $4.70 \pm 0.55^{\mathrm{d}}$ & $1.62 \pm 0.15^{\mathrm{d}}$ & $0.42 \pm 0.04^{\mathrm{d}}$ \\
$\mathrm{Nd}+\mathrm{Cr}$ & $0.70 \pm 0.09^{\mathrm{c}}$ & $0.42 \pm 0.05^{\mathrm{c}}$ & $0.39 \pm 0.04^{\mathrm{a}}$ & $0.36 \pm 0.47^{\mathrm{c}}$ & $5.80 \pm 0.64^{\mathrm{c}}$ & $1.86 \pm 0.22^{\mathrm{c}}$ & $0.53 \pm 0.06^{\mathrm{c}}$ \\
\hline
\end{tabular}

Table 3. Effects of $\mathrm{NdCl}_{3}$ on the contents of $\mathrm{Nd}$ and $\mathrm{Cr}$ in wheat roots and leaves under $\mathrm{Cr}$ stress. The plants were treated as in Table 2. The plants were firstly treated by $\mathrm{NdCl}_{3}$ for $12 \mathrm{~h}$, and then treated by $\mathrm{Cr}$ stress for $7 \mathrm{~d}$. Values are means $\pm \mathrm{SD}, n=6$. Different lowercase letters mean statistical difference at $5 \%$ level of significance.

\begin{tabular}{llccc}
\hline Treatment & $\begin{array}{l}\text { Nd content in leaves } \\
{\left[\mathrm{mg} \mathrm{kg}^{-1}(\mathrm{DM})\right]}\end{array}$ & $\begin{array}{c}\mathrm{Nd} \text { content in roots } \\
{\left[\mathrm{mg} \mathrm{kg}^{-1}(\mathrm{DM})\right]}\end{array}$ & $\begin{array}{l}\text { Cr content in leaves } \\
{\left[\mathrm{mg} \mathrm{kg}^{-1}(\mathrm{DM})\right]}\end{array}$ & $\begin{array}{l}\text { Cr content in roots } \\
{\left[\mathrm{mg} \mathrm{kg}^{-1}(\mathrm{DM})\right]}\end{array}$ \\
\hline Control & $0.16 \pm 0.02^{\mathrm{c}}$ & $0.46 \pm 0.05^{\mathrm{c}}$ & $3.00 \pm 0.26^{\mathrm{c}}$ & $10.30 \pm 1.30^{\mathrm{c}}$ \\
$\mathrm{Nd}$ & $4.40 \pm 0.49^{\mathrm{a}}$ & $26.70 \pm 3.15^{\mathrm{a}}$ & $2.50 \pm 0.22^{\mathrm{c}}$ & $8.80 \pm 0.74^{\mathrm{c}}$ \\
$\mathrm{Cr}$ & $0.13 \pm 0.02^{\mathrm{c}}$ & $0.40 \pm 0.04^{\mathrm{c}}$ & $41.00 \pm 4.77^{\mathrm{a}}$ & $390.60 \pm 47.80^{\mathrm{a}}$ \\
$\mathrm{Nd}+\mathrm{Cr}$ & $3.20 \pm 0.44^{\mathrm{b}}$ & $21.90 \pm 1.83^{\mathrm{b}}$ & $27.20 \pm 2.80^{\mathrm{b}}$ & $264.70 \pm 33.16^{\mathrm{b}}$ \\
\hline
\end{tabular}

Table 4. Effects of $\mathrm{NdCl}_{3}$ on malondialdehyde (MDA) content, electrolyte leakage (EL), root length, plant height, and plant biomass of wheat under $\mathrm{Cr}$ stress. The plants were treated as in Table 2 . The plants were firstly treated by $\mathrm{NdCl}_{3}$ for $12 \mathrm{~h}$, and then treated by $\mathrm{Cr}$ stress. After $48 \mathrm{~h}$ of treatment, MDA content was determined. After $7 \mathrm{~d}$ of treatment, plant height and biomass were determined. Values are means $\pm \mathrm{SD}, n=6$. Different lowercase letters mean statistical difference at $5 \%$ level of significance.

\begin{tabular}{lclllc}
\hline Treatment & $\begin{array}{l}\text { MDA content } \\
{\left[\mathrm{nmol} \mathrm{g}{ }^{-1}(\mathrm{FM})\right]}\end{array}$ & $\begin{array}{l}\text { EL } \\
{[\%]}\end{array}$ & $\begin{array}{l}\text { Plant height } \\
{[\mathrm{cm}]}\end{array}$ & $\begin{array}{l}\text { Root length } \\
{[\mathrm{cm}]}\end{array}$ & $\begin{array}{l}\text { Plant biomass } \\
{\left[\mathrm{mg}(\mathrm{FM}) \text { plant }^{-1}\right]}\end{array}$ \\
\hline Control & $5.70 \pm 0.66^{\mathrm{c}}$ & $12.80 \pm 1.01^{\mathrm{c}}$ & $16.30 \pm 1.37^{\mathrm{b}}$ & $13.70 \pm 1.55^{\mathrm{b}}$ & $104.70 \pm 9.46^{\mathrm{b}}$ \\
$\mathrm{Nd}$ & $4.30 \pm 0.39^{\mathrm{d}}$ & $10.00 \pm 0.86^{\mathrm{d}}$ & $18.80 \pm 1.95^{\mathrm{a}}$ & $15.50 \pm 1.80^{\mathrm{a}}$ & $118.50 \pm 12.22^{\mathrm{a}}$ \\
$\mathrm{Cr}$ & $13.30 \pm 1.17^{\mathrm{a}}$ & $29.50 \pm 2.12^{\mathrm{a}}$ & $12.00 \pm 1.41^{\mathrm{d}}$ & $9.50 \pm 1.11^{\mathrm{d}}$ & $77.20 \pm 6.19^{\mathrm{d}}$ \\
$\mathrm{Nd}+\mathrm{Cr}$ & $9.00 \pm 0.84^{\mathrm{b}}$ & $20.20 \pm 1.83^{\mathrm{b}}$ & $14.20 \pm 1.36^{\mathrm{c}}$ & $11.70 \pm 1.33^{\mathrm{c}}$ & $90.80 \pm 9.47^{\mathrm{c}}$ \\
\hline
\end{tabular}

(2006), Farid et al. (2018), and Kabir (2016). Besides, our results showed that $\mathrm{Cr}$ stress markedly improved the activities of DHAR and MDHAR in wheat leaves. The present results indicated that wheat could fight against $\mathrm{Cr}$ stress through AsA-GSH cycle at physiological level. The redox state of plants has close relationships with AsA/DHA and GSH/GSSG, which can be modulated by AsA-GSH cycle. In this study, our present findings showed that $\mathrm{Cr}$ stress improved the activities of APX, GR, DHAR, and MDHAR. However, our study showed that $\mathrm{Cr}$ stress reduced AsA/DHA and GSH/GSSG, which was because of the oxidative stress induced by $\mathrm{Cr}$ stress. Liu et al. (2020) reported that Cr stress significantly downregulated the expression of genes involved in redox process and upregulated the expression of genes involved in the stress response in Arabidopsis thaliana, which was proved by our current results by analyzing the activities of enzymes responsible for the redox states of ascorbate and glutathione.
Previous studies showed that REEs $\mathrm{La}$ and $\mathrm{Ce}$ all increased AsA/DHA and GSH/GSSG ratios by activating AsA-GSH cycle in plants (Dai et al. 2017, Zheng and Guo 2018). Under heavy metal stress, Dai et al. (2017) showed that La improved cadmium tolerance of maize seedlings by regulating AsA/DHA and GSH/GSSG through the enhancement of AsA-GSH cycle. For current study, our results showed that $\mathrm{Nd}$ improved the activities of APX, GR, DHAR, and MDHAR, which further maintained AsA/DHA and GSH/GSSG and improved the antioxidant capacity of wheat plants. Thus, our results showed that $\mathrm{Nd}$ improved the antioxidant capacity of wheat crops by enhancing AsA-GSH cycle. These findings were the novelty of current study. Besides, previous studies showed that La and $\mathrm{Ce}$ had positive effects on stress tolerance of plants at low concentrations, but had negative effects at high concentrations. For the present study, we also found that $\mathrm{Nd}$ had the same effects as other REEs in previous studies. Therefore, the results of previous and our present 
studies may confirm that low concentrations of REEs had positive effects on the stress tolerance of plants.

It has been documented that the function of chloroplasts was closely related with the antioxidant capacity and the contents of photosynthetic pigments (Chen and Shan 2019). For the present study, our results clearly showed that $\mathrm{Nd}$ partly alleviated the negative effects of $\mathrm{Cr}$ on the contents of photosynthetic pigments $\mathrm{Chl}$ and Car. This phenomenon indicated that $\mathrm{Nd}$ alleviated $\mathrm{Cr}$-induced oxidative damage to photosynthetic pigments by enhancing the antioxidant capacity through AsA-GSH cycle. In addition, we found that $\mathrm{Nd}$ partly alleviated the negative effects of $\mathrm{Cr}$ stress on chloroplast function indicated by the Chl fluorescence parameters. In this study, $\mathrm{Cr}$ stress markedly reduced $\mathrm{F}_{\mathrm{v}} / \mathrm{F}_{\mathrm{m}}, \Phi_{\mathrm{PSII}}$, and $\mathrm{q}_{\mathrm{P}}$, which implied that $\mathrm{Cr}$ stress inhibited the electron transport and photochemical activity of PSII. While, Nd plus Cr stress markedly improved $\mathrm{F}_{\mathrm{v}} / \mathrm{F}_{\mathrm{m}}$, $\Phi_{\text {PSII }}$, and $\mathrm{q}_{\mathrm{P}}$, which suggested that $\mathrm{Nd}$ promoted the photochemical conversion efficiency and photochemical activity of PSII in Cr-stressed wheat seedlings. However, Cr stress markedly improved $\mathrm{q}_{\mathrm{N}}$, which indicated that wheat crops enhanced the photoprotective capacity under $\mathrm{Cr}$ stress. Meanwhile, we found that $\mathrm{Nd}$ further enhanced the photoprotective capacity of wheat crops by improving $\mathrm{q}_{\mathrm{N}}$ under $\mathrm{Cr}$ stress. Therefore, our findings indicated that $\mathrm{Nd}$ improved the function of chloroplast by enhancing AsA-GSH cycle, which further promoted the growth of wheat seedlings.

Many studies showed that the injury induced by $\mathrm{Cr}$ stress has a close relationship with its accumulation in the organs of plants (Habiba et al. 2019, Zhao et al. 2019). In this study, we also found that $\mathrm{Cr}$ stress stimulated its accumulation in the roots and leaves of wheat seedlings. Besides, we found that $\mathrm{Nd}$ markedly reduced $\mathrm{Cr}$ accumulation in the roots and leaves of wheat seedlings, which further reduced the inhibitory effects of $\mathrm{Cr}$ stress on wheat seedlings.

The present results suggested that $\mathrm{NdCl}_{3}$ improved the antioxidant capacity and the function of photosystem by enhancing the activity of AsA-GSH cycle, which, in turn, protected wheat seedlings against $\mathrm{Cr}$ stress. Our results provided new information for the roles of $\mathrm{Nd}$ in regulating the antioxidant mechanism of wheat crops under Cr stress.

\section{References}

Ahmad P., Ahanger M.A., Alyemeni M.N. et al.: Exogenous application of nitric oxide modulates osmolyte metabolism, antioxidants, enzymes of ascorbate-glutathione cycle and promotes growth under cadmium stress in tomato. Protoplasma 255: 79-93, 2018.

Anjum S.A., Tanveer M., Hussain S. et al.: Cadmium toxicity in maize (Zea mays L.): consequences on antioxidative systems, reactive oxygen species and cadmium accumulation. Environ. Sci. Pollut. R. 22: 17022-17030, 2015.

Bradford M.M.: A rapid and sensitive method for the quantitation of microgram quantities of protein utilizing the principle of protein-dye binding. - Anal. Biochem. 72: 248-254, 1976.

Chen X.D., Shan C.J.: Cerium nitrate improves salt tolerance of wheat seedlings by regulating the antioxidant capacity of chloroplasts. - Biol. Plantarum 63: 323-327, 2019.
Dai H., Shan C., Zhao H. et al.: Lanthanum improves the cadmium tolerance of Zea mays seedlings by the regulation of ascorbate and glutathione metabolism. - Biol. Plantarum 61: 551-556, 2017.

Dalton D.A., Russell S.A., Hanus F.J. et al.: Enzymatic reactions of ascorbate and glutathione that prevent peroxide damage in soybean root nodules. - P. Natl. Acad. Sci. USA 83: 3811$3815,1986$.

Farid M., Ali S., Rizwan M. et al:: Phyto-management of chromium contaminated soils through sunflower under exogenously applied 5-aminolevulinic acid. - Ecotox. Environ. Safe. 151: 255-265, 2018.

Habiba U., Ali S., Rizwan M. et al.: Alleviative role of exogenously applied mannitol in maize cultivars differing in chromium stress tolerance. - Environ. Sci. Pollut. R. 26: 5111-5121, 2019.

Han S., Fang L., Ren X. et al.: MPK6 controls $\mathrm{H}_{2} \mathrm{O}_{2}$-induced root elongation by mediating $\mathrm{Ca}^{2+}$ influx across the plasma membrane of root cells in Arabidopsis seedlings. - New Phytol. 205: 695-706, 2015.

Heath R.L., Packer L.: Photoperoxidation in isolated chloroplasts. I. Kinetics and stoichiometry of fatty acid peroxidation. Arch. Biochem. Biophys. 125: 189-198, 1968.

Hodges D.M., Andrews C.J., Johnson D.A., Hamilton R.I.: Antioxidant compound responses to chilling stress in differentially sensitive inbred maize lines. - Physiol. Plantarum 98: 685-692, 1996.

Kabir A.H.: Biochemical and molecular changes in rice seedlings (Oryza sativa L.) to cope with chromium stress. - Plant Biol. 18: 710-719, 2016.

Karuppanapandian T., Sinha P.B., Haniya A.M.K., Mamoharan K.: Differential antioxidative responses of ascorbate-glutathione cycle enzymes and metabolites to chromium stress in green gram (Vigna radiata L. Wilczek) leaves. - J. Plant Biol. 49: 440-447, 2006.

Li L., Hou M.J., Cao L. et al.: Glutathione S-transferases modulate $\mathrm{Cu}$ tolerance in Oryza sativa. - Environ. Exp. Bot. 155: 313-320, 2018.

Li W., Zhao F.A., Fang W.P. et al.: Identification of early salt stress responsive proteins in seedling roots of upland cotton (Gossypium hirsutum L.) employing iTRAQ-based proteomic technique. - Front. Plant Sci. 6: 732, 2015.

Lichtenthaler H.K., Wellburn A.L.: Determination of total carotenoids and chlorophylls $a$ and $b$ of leaf extracts in different solvents. - Biochem. Soc. T. 11: 591-593, 1983.

Liu J.X., Ding G.T., Gai Z.K. et al.: Changes in the gene expression profile of Arabidopsis thaliana under chromium stress. - Ecotox. Environ. Safe. 193: 110302, 2020.

Ma J., Lv C., Xu M. et al.: Photosynthesis performance, antioxidant enzymes, and ultrastructural analyses of rice seedlings under chromium stress. - Environ. Sci. Pollut. R. 23: 1768-1778, 2016.

Mahmud J.A.L., Hasanuzzaman M., Nahar K. et al.: $\gamma$-aminobutyric acid (GABA) confers chromium stress tolerance in Brassica juncea L. by modulating the antioxidant defense and glyoxalase systems. - Ecotoxicology 26: 675-690, 2017.

Nakano Y., Asada K.: Hydrogen peroxide is scavenged by ascorbate specific peroxidase in spinach chloroplasts. - Plant Cell Physiol. 22: 867-880, 1981.

Ouyang J., Wang X.D., Zhao B. et al.: Effects of rare-earth elements on the growth of Cistanche deserticola cells and the production of phenylethanoid glycosides. - J. Biotechnol. 102: 129-134, 2003.

Qing X., Zhao X., Hu C. et al.: Selenium alleviates chromium toxicity by preventing oxidative stress in cabbage (Brassica campestris L. ssp. Pekinensis) leaves. - Ecotox. Environ. 
Safe. 114: 179-189, 2015.

Shan C., Zhang H., Zhang Y., Zhou H.: Lanthanum nitrate regulates the content of vitamin $\mathrm{C}$ through its biosynthesis, regeneration and degradation in the fruit of strawberry. - Sci. Hortic.-Amsterdam 224: 102-108, 2017.

Shan C., Zhang Y., Zhang H.: ABA participates in the regulation of vitamin $\mathrm{C}$ content in the fruit of strawberry using lanthanum nitrate. - Sci. Hortic.-Amsterdam 233: 455-459, 2018.

Singh P.K., Wang W., Shrivastava A.K.: Cadmium-mediated morphological, biochemical and physiological tuning in three different Anabaena species. - Aquat. Toxicol. 202: 36-45, 2018.

Song Y.W., Xiang F.Y., Zhang G.Z. et al.: Abscisic acid as an internal integrator of multiple physiological processes modulates leaf senescence onset in Arabidopsis thaliana. Front. Plant Sci. 7: 181, 2016.

Tan J.J., He S.B., Yan S.H. et al.: Exogenous EDDS modifies copper-induced various toxic responses in rice. - Protoplasma 251: 1213-1221, 2014.

Trinh N.N., Huang T.L., Chi W.C. et al.: Chromium stress response effect on signal transduction and expression of signaling genes in rice. - Physiol. Plantarum 150: 205-224, 2014.

Wang R., Wang Y., Ma X.: [Effect of La and Ce on antioxidant enzymes system of pea seedlings under copper stress.] -
J. Nucl. Agr. Sci. 27: 873-878, 2013. [In Chinese]

Wang Z.Q., Yang C.L., Chen H. et al.: Multi-gene co-expression can improve comprehensive resistance to multiple abiotic stresses in Brassica napus L. - Plant Sci. 274: 410-419, 2018.

Xue Z.C., Li J.H., Li D.S. et al.: Bioaccumulation and photosynthetic activity response of sweet sorghum seedling (Sorghum bicolor L. Moench) to cadmium stress. Photosynthetica 56: 1422-1428, 2018.

Yu J.J., Zhang Y.X., Liu J.M. et al.: Proteomic discovery of $\mathrm{H}_{2} \mathrm{O}_{2}$ response in roots and functional characterization of PutGLP gene from alkaligrass. - Planta 248: 1079-1099, 2018.

Zhang X.L., Zhao X.L., Li B.Z. et al.: SRO1 regulates heavy metal mercury stress response in Arabidopsis thaliana. Chinese Sci. Bull. 59: 3134-3141, 2014.

Zhao Q., Chen W.X., Bian J.Y. et al.: Proteomics and phosphoproteomics of heat stress-responsive mechanisms in spinach. - Front. Plant Sci. 9: 800, 2018.

Zhao Y.Y., Hu C.X., Wang X. et al.: Selenium alleviated chromium stress in Chinese cabbage (Brassica campestris L. ssp. Pekinensis) by regulating root morphology and metal element uptake. - Ecotox. Environ. Safe. 173: 314-321, 2019.

Zheng M., Guo Y.: Cerium improves the vase life of Dianthus caryophyllus cut flower by regulating the ascorbate and glutathione metabolism. - Sci. Hortic.-Amsterdam 240: 492495, 2018.

(C) The authors. This is an open access article distributed under the terms of the Creative Commons BY-NC-ND Licence. 